\title{
Perceived Life Satisfaction and Social Support of Aged during COVID-19 Outbreaks: A Study of New Delhi
}

Hena Gauhar ${ }^{1 *}$, Prof. (Dr.) Anis Ahmad ${ }^{2}$

${ }^{1}$ PhD Scholar, University Department of Psychology, L. N. Mithila University, Darbhanga - 846004, India

${ }^{2}$ Professor, University Department of Psychology, L. N. Mithila University, Darbhanga - 846 004, India

\begin{abstract}
DOI: $10.36348 /$ sjhss.2020.v05i08.007 $\quad$ | Received: 16.08 .2020 | Accepted: 24.08.2020 | Published: 28.08 .2020
\end{abstract}
*Corresponding author: Hena Gauhar

\section{Abstract}

The present research endeavor was aimed at studying the perceived life satisfaction and social support of aged men and women during COVID - 19 outbreaks with special reference to New Delhi, India. For the present piece of research work total sample one hundred sixty $(\mathrm{N}=160)$ comprising aged women $(\mathrm{n}=80)$ and aged men $(\mathrm{n}=80)$ randomly selected from different locality of New Delhi. Subjects' age were ranged between 60-75 years. Data collected door to door by maintaining social distance through questionnaires schedules individually from aged women and men during COVID-19 outbreaks. During the data collection respondents were taken in to confidence and assured them that responses provided by them on the items of questionnaire schedules will be kept strictly confidential. Having tabulated and analyzed the data, results revealed the fact that there is high significant difference between the group of aged men and women towards their degree of perceived life satisfaction which has been statistically found significant at .01 level of confidence, although, aged women were found more prone to higher degree of life satisfaction than men during the novel COVID-19 outbreaks. Moreover, aged women have shown higher degree of social support than aged men, hence, significant difference have also been found between the group of aged men and women at .01 level of confidence towards their life satisfaction. The discrepancies of results obtained have been discussed in detail by giving probable reasons.

Keywords: Life Satisfaction, Social Support, Aged Men and Women, COVID-19, New Delhi.

Copyright @ 2020: This is an open-access article distributed under the terms of the Creative Commons Attribution license which permits unrestricted use, distribution, and reproduction in any medium for non-commercial use (NonCommercial, or CC-BY-NC) provided the original author and source are credited.

\section{INTRODUCTION}

Daily life is being adversely affected now-adays by stress due to novel COVID-19 outbreaks and it deteriorates our life satisfaction and at this juncture every men and women especially aged needs social support for maintaining his/her degree of life satisfaction. Hence, the present research investigation was aimed at studying the perceived Life Satisfaction in relation to perceived Social Support with reference to aged men and women with particular reference to New Delhi, India.

The novel corona virus disease that emerged at the end of 2019 began threatening the health and lives of millions of people after a few weeks. Highly contagious with the possibility of causing severe respiratory disease, it has quickly impacted governments and public health systems. These have responded by declaring a public health emergency of national and international concern, as well as by adopting extraordinary measures to prevent the contagion and limit the outbreak. Millions of lives have been significantly altered, and a global, multi-level, and demanding stress-coping-adjustment process is ongoing.

The COVID-19 disease has now achieved pandemic status. The World Health Organization has issued guidelines for managing the problem from both biomedical and psychological points of view. While preventive and medical action is the most important at this stage, emergency psychological crisis interventions for people affected by COVID-19 are also critical. This includes direct interventions for patients, and indirect for relatives, caregivers, and health care professionals. Thus, the study of life satisfaction of aged in relation to social support during novel COVID-19 is of utmost value.

Life satisfaction, morale and happiness are often used interchangeably referring to psychological well being of the individual. Psychological well-being includes mental functioning such as happiness, morale, 
life satisfaction, and the absence of psychopathology (e.g. depression). George [1] defined life satisfaction as a cognitive process by which an individual assesses his/her progress towards desired goals. George also defined happiness as "transitory moods of gaiety reflecting the affect that people feel toward their current state of affairs". Finally she defined morale as fit between the individual and the environment, the acceptance of those aspects of life that can not be changed and more generally it depends on how positive one's outlook of life is. In addition to these, it is generally observed that motivational spheres of life contribute a lot to getting individual's life satisfaction which provides all round capacity with commitment of work and family.

Old age is the fading period of life cycle. It is a period when people move away from hay day of life, full of power, vitality and happiness. According to Hurlock [2] age sixty is often considered as the dividing line between middle age and old age. The last stage in lifespan is subdivided into early old age, which extends from age sixty to seventy, and advance old age, which begins at seventy and extends to the end of life. Thus old age has been viewed either as a transition that is accompanied by psychological distress or as a time of continued, or even enhanced, subjective wellbeing. Palmore and Kivett [3] have pointed out that the best predictor of life satisfaction is the person's ratings of life satisfaction in the past and that initial values or changes in other variables appeared to be unrelated to changes in life satisfaction. Moreover, Taves and Hansen [4] point out that health problem appear to detract from enjoying a number of close friendships, satisfaction with work, and satisfaction with family. Whereas various researches have shown that life satisfaction may also affect health when a person is dissatisfied with life, it means that an individual is experiencing negative vive that are coloring his/her view of the world around him/her. There may also be relative lack of positive feelings due to radical change in the state of mind. Such dissatisfaction means important needs and expectations that are not being met as pointed out by Lawton [5].

During reviewing the literature on the life satisfaction it was observed that there are basically two approaches to life satisfactions. The first focuses upon the overt behavior of the individual and uses social criteria of success and competence. The second approach is to be viewed from an individual's internal frame i.e. the individual's own interpretation and evaluation of his present or past life, and his satisfaction or his happiness. Thus the present article is approached to study on the social criteria of life satisfaction during the period of COVID-19 pandemic to get successful aging. Hence, the present endeavor will fill the void of knowledge in the area of aging.
In the times of COVID-19 outbreaks, impact of social support on life satisfaction has attracted the interest of psychologists, behaviorists, public health professionals and NGOs having different perspectives and orientations. However, Social support refers to helpful social interactions that make people feel better. People who interact closely with friends and relatives are better able to avoid illness and if illness occurs, to recover from it sooner than those who are interpersonally isolated.

Social support may be in several forms such as family, community, and other social institutions like religious and state. The rising number of literature documents the importance of social support network in maintaining good morale, happiness, psychological well-being and life satisfaction. Hence, adequate social support system helps individuals avoid internalizing diminished views of them. The greater integration in a social network is associated with fewer mental and physical health problems [6]. Social support as information that leads the individual to believe that he/she is cared and loved, esteemed and valued, and that he belongs to a network of communication and mutual obligations [7].

\section{OBJECTIVE OF THE PRESENT STUDY}

On the basis of past researches and self observations the present research investigation was aimed to assess the perceived life satisfaction of elderly and to find out its relationship with social support availed by them especially during the period of COVID-19 pandemic. Various study of Life Satisfaction have been found by reviewing the literature available but none of the study was found with reference to New Delhi aged people. Thus, the present study is of immense value in the area concerned and the findings will help to understand the behavior of elderly people during the period of novel COVID-19 outbreaks especially in New Delhi and the whole study will fill the void of knowledge in the area chosen by present investigators.

\section{HYPOTHESES}

On the basis of the above mentioned broad objectives the following hypotheses have been formulated.

1. There will not be significant difference between the group of aged men and women in terms of their degree of perceived Life Satisfaction during COVID-19

2. There will not be significant difference between the group of aged men and women in terms of their degree of perceived Social Support during COVID-19

3. Aged women will differ from men in terms of their degree of perceived Life Satisfaction and on their degree of perceived Social Support as well during COVID-19. 


\section{METHODOLOGY}

Sample

For the present piece of research work total sample one hundred sixty $(\mathrm{N}=160)$ comprising aged men $(n=80)$ and aged women $(n=80)$ were randomly selected from different locality of New Delhi. All subjects included in the sample were contacted personally from different area of locality of New Delhi, namely, Okhla, Zakir Nagar, Batla House, Shaheen Bagh, Ghafoor Nagar, Abul Fazal Enclave, and_Malviya Nagar. The subjects' age ranged between $60-7 \overline{5}$ years.

\section{Tools Used}

The following measures / tools were used for the present piece of research work.

\section{Life Satisfaction Scale}

For measuring the degree of life satisfaction of the aged women, aged working women and aged men a scale developed by Chadha \& Van Willigen [8] was used. The scale assesses life satisfaction as an individual's interpretation of his past and present life and consequent happiness and satisfaction. This scale is particularly designed to measure the construct of life satisfaction among older adults in an Indian cultural setting. The scale consists of 27 items based on Likert type 7 - point scale in which 12 items are scored in reverse order i.e. 7 to 1 (for strongly disagree to strongly agree). In this scale, higher score indicates high life satisfaction. The scale has a high reliability value of 0.95 and is therefore a good measure of life satisfaction for the elderly population.

\section{Social Support Questionnaire}

For measuring perception of social support, a scale developed by Nehra, Kulhara and Verma [9] was used. The questionnaire consists of 18 items having four alternative responses. In positive items, score of 4 will be given to most agreed, 3 to agreed, 2 for to some extent and 1 to least agreed. In this questionnaire schedule, 11 items are negatively phrased; hence, these items have to be scored in the reverse order. The total score indicates the amount of Social Support perceived by the individual. Higher score indicates more perceived social support.

\section{Biographical Information Blank (BIB)}

For tapping biographical information of the subjects, a biographical information blank (BIB) was also prepared by the present investigator for the present research work. It includes age, qualification, family structure (joint \& nuclear), religion, marital status (married, unmarried, widows, non - widows), working/non-working, family income, source of income, Area of locality (Urban and Rural) etc. and the respondents were requested to furnish these information.

\section{Procedures}

The above mentioned two test materials along with Biographical Information Blank (BIB) were administered in printed from individually on all aged women and men from different localities as above stated. During the collection of data all the subjects were assured by taking in to confidence that provided information will be kept strictly confidential and will be used for research purposes only.

Having collected the responses to the items of the questionnaire schedule, they were scored according to the procedures and the individual scores were obtained. Finally scores were given statistical treatment and presented in the tables. The obtained results were discussed and the formulated hypotheses were tested.

\section{RESULTS AND DISCUSSION}

In quest of investing the objective of the present piece of research work on "Perceived Life Satisfaction of Aged Men and Women in relation to Social Support with particular to New Delhi, India", the results obtained have been given below:

Table-1: Showing Differences between the mean, SD and $\mathbf{t}$ - value Between the Group of Aged Men and Women on their Degree of Perceived Life Satisfaction

\begin{tabular}{|l|l|l|l|l|l|}
\hline Group & $\mathbf{N}=\mathbf{1 6 0}$ & Mean & S. D & t & Level of significance \\
\hline Aged Men & $\mathrm{n}=80$ & 125.23 & 31.31 & 6.08 & 0.01 \\
\hline Aged Women & $\mathrm{n}=80$ & 159.31 & 38.72 & & \\
\hline
\end{tabular}

Table- 1 of the results has revealed the fact that the mean scores of perceived life satisfaction among aged women is quite high in comparison to aged men, hence, the very high differences have been found as the mean score of aged men have been found low on life satisfaction score. Although, aged women scored higher degree of perceived life satisfaction as the mean scores is 159.31 with SD 38.72, and aged men scored mean 125.23 with SD 31.31 respectively. As the hypothesis formulated that there will not be significant difference between the group of aged men and aged women on their perceived reactions of life satisfaction stand rejected and their ' $t$ ' value 6.08 have been found highly significant at .01 level of confidence.

In addition to the Table- 1 of the results, from table -2 it can also be observed the levels of perceived life satisfaction among aged men and aged women comparatively. 
Table-2: Showing Levels of Perceived Life Satisfaction among Aged Men and Women

\begin{tabular}{|l|l|l|l|l|}
\hline \multirow{2}{*}{ LEVELS } & \multicolumn{2}{|c|}{ Aged Men } & \multicolumn{2}{c|}{ Aged Women } \\
\cline { 2 - 5 } & $\mathbf{n = 8 0}$ & Percentage & $\mathbf{n = 8 0}$ & Percentage \\
\hline High & 45 & $56.25 \%$ & 51 & $63.75 \%$ \\
\hline Moderate & 20 & $25.00 \%$ & 18 & $22.5 \%$ \\
\hline Low & 15 & $18.75 \%$ & 11 & $13.75 \%$ \\
\hline
\end{tabular}

Mean=159.31 Mean=125.23

Table-2 have revealed that $63.75 \%$ of old age women have shown higher degree of acceptability towards the degree of perceived life satisfaction during the novel COVID - 19 pandemic but on the other hand, $56.25 \%$ of old age men have shown higher degree of their perceived reactions towards life satisfaction which is quite low in comparison to their women counterparts. $25.00 \%$ of old age men have their moderate level of acceptability and $22.25 \%$ of old age women have shown moderate level of acceptability to life satisfaction than the group of old age men. $13.75 \%$ of old age women have shown low levels of perceived life satisfaction, whereas $18.75 \%$ of old age men have shown low level of perceived reactions of life satisfaction but both the group has shown quite little favorable reactions on their perceived life satisfaction. It is because of the fact that the mean scores of both the groups are high given in the beneath of the table i.e. Mean $=159.31$ (for women) and Mean $=125.23$ (for men) respectively as the maximum scores of life satisfaction scale is 189 . The results presented in Table2 can also be observed by the following diagram:

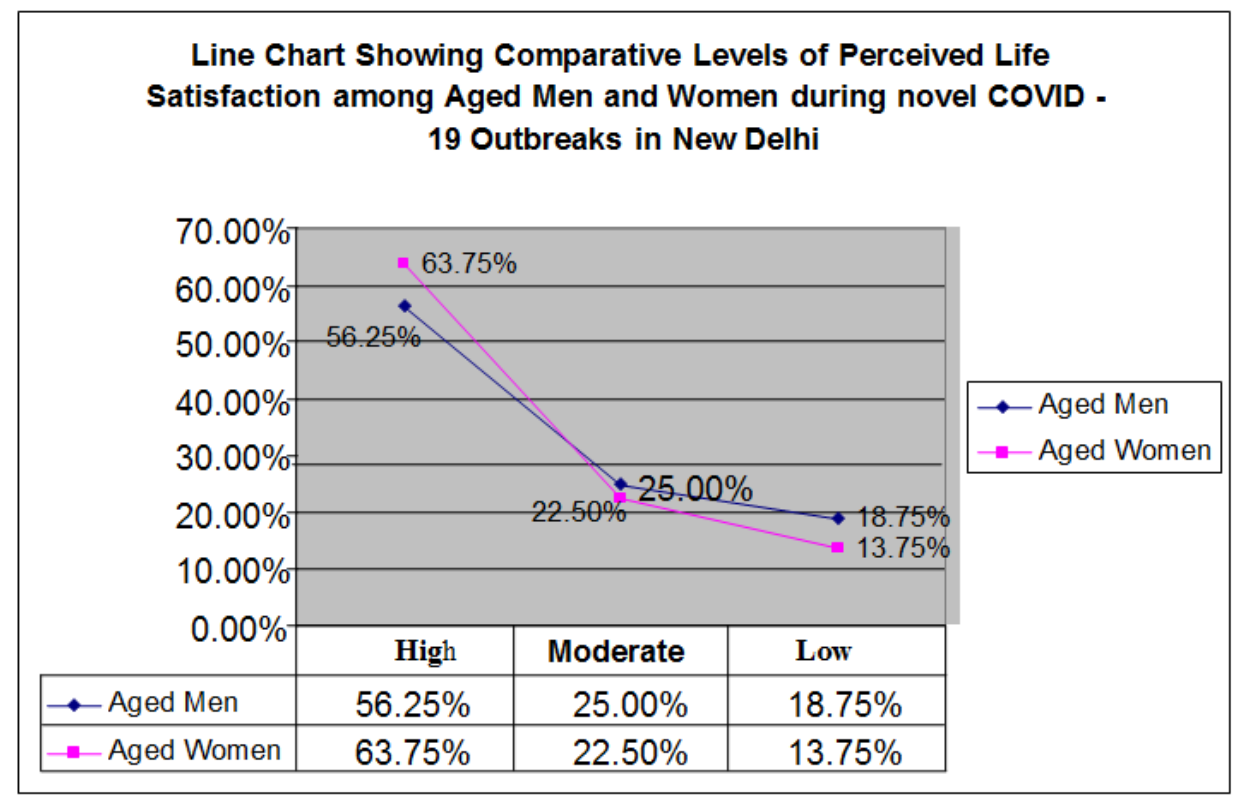

While tabulating and calculating the individual data on social support towards life satisfaction during COVID-19 pandemic, it has been observed from the Table -3 of the results that old age women scored higher degree of social support than their male counterparts. Hence, the significant difference has been found at .05 level of confidence. Therefore, the proposed hypothesis that there will not be significant difference between the group of aged men and women in terms of their degree of perceived Social Support also stands rejected. It is because of the fact that the obtained scores of social support have been found little quite high as the maximum scores of social support is 72. Thus, the obtained scores on social support is quite favorable but between the two groups as stated above have been found significant at .05 levels of confidence.

Table- 4 of the results depict the clear cut picture regarding the levels of perceived reactions to social support between the group of aged men and women comparatively.

Table-3: Showing Differences between the Mean Scores of Social Support between the Aged Men and Women group on Perceived Life Satisfaction

\begin{tabular}{|c|l|l|l|l|l|}
\hline Group of Aged & $\mathbf{N}=\mathbf{1 6 0}$ & Mean & S.D & 't' & Level of significance \\
\hline Aged Men & $\mathrm{n}=80$ & 45.73 & 8.34 & 2.53 & 0.05 \\
Aged Women & $\mathrm{n}=80$ & 48.74 & 6.57 & & \\
\hline
\end{tabular}


Table-4: Showing Comparative Levels of Perceived Social Support among Aged Men and Women in Ara, Bihar, India

\begin{tabular}{|l|l|l|l|l|}
\hline \multirow{2}{*}{ LEVELS } & OLD AGE MEN & OLD AGE WOMEN \\
\cline { 2 - 5 } & $\mathbf{n = 8 0}$ & Percentage & $\mathbf{n = 8 0}$ & Percentage \\
\hline High & 39 & $48.75 \%$ & 48 & $60.00 \%$ \\
\hline Moderate & 30 & $37.5 \%$ & 24 & $30.00 \%$ \\
Low & 11 & $13.75 \%$ & 08 & $10.00 \%$ \\
\hline
\end{tabular}

Elaborating the Table-4 with regard to the levels of perceived social support among old age men and old age women that indicated that $60.00 \%$ of old age women especially in Ara, Bihar area had higher levels of social support in comparison to old age men i.e. $48.75 \%$ which is comparatively low from old age women, whereas, $37.5 \%$ of old age men have shown moderate levels of social support in comparison to old age women i.e. $30.00 \%$ and moreover, $10.00 \%$ of old age women have reported low level of social support than old age men i.e. $13.75 \%$ which is comparatively high from their female counterparts. Although both the group of aged men and women have indicated favorable inclination towards social support on their degree of perceived life satisfaction as their mean scores of social support are $\mathrm{X}=45.73$ (for men) and $\mathrm{X}=48.74$ (for women) which are very satisfactory as the maximum score of the scale is 72 . The results presented in Table4 can also be observed by the following diagram:

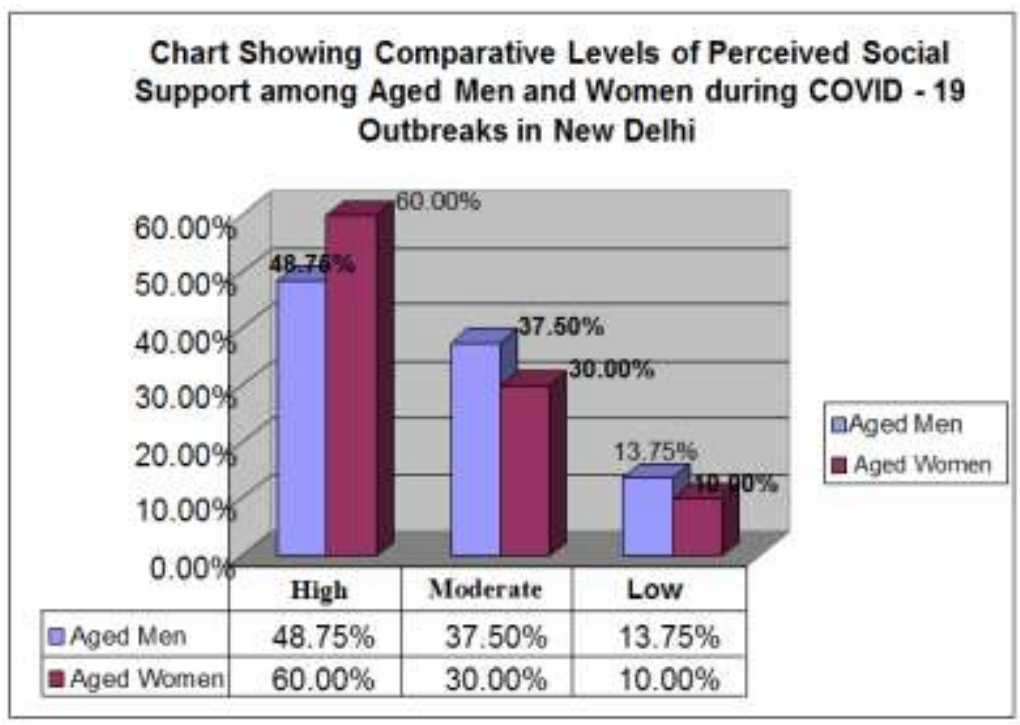

Discussing the results obtained, it is important to be mentioned that higher degree of significant differences between the aged group of women and men on the degree of life satisfaction have been found and moreover, social support as well have been found significant difference as their $\mathrm{t}$ - values have been found statistically significant at .05 level of confidence. The obtained results especially from where the sample has been drawn seem to be logical, in the sense that when people grow older and older, their behaviors become typically different. At that time they become motivated towards spiritual and social life. They usually prefer to get involved in religious group and think about spiritual practices. Hence, both the group of aged men and women have shown higher degree of perceived inclination to life satisfaction but women have been found more prone to life satisfaction during COVID-19 outbreaks. The present obtained result can also be interpreted that everybody wants to be happy, no matter the age; that's why it's no surprise that even elderly women are seeking happiness in life. It is also important to be mentioned that enjoyment in life, a sense of purpose, and happiness can still elude elderly women even during this pandemic outbreaks, making these all the more important to attain, especially in one's advanced years in life [10].

Having discussed the results pertaining to life satisfaction of aged women, table -3 and 4 have shown the picture regarding differences between the mean scores of social support of aged men and women towards life satisfaction which reveals the fact that the women were prone to have social support than the group of aged men even during this novel COVID-19 break. The obtained results is quite favorable in the sense that in Indian society still elderly are getting more assistance and benefit from joint family structure. Because family members cares of them by remembering that every individual will taste of it if he/she alive on earth. The tendencies of these results are to be pointed out here that the status of women in India is not much different from that in other cultures. As a 
product of biology in part and to a great extent socialization practices perhaps women tend to be different psychologically than men. They are more sensitive than men to social interaction, develop closer and more extensive social network and are more giving in these relationships $[11,12]$. It seems that because of this greater sensitivity and emotionality, perhaps, the group of old age women are more likely to seek help than their counterparts viz, old age men. Thus, they have been found to be significant difference interns of social support.

\section{CONCLUSIONS}

In the light of the obtained results and discussions, the following conclusions were summed-up:

1. Significance of difference has been found between the group of old age men and women in their degree of perceived reactions towards life satisfaction in New Delhi.

2. Old age women were found more prone to life satisfaction than old age men especially in New Delhi - India from where the present piece of research work has been carried out.

3. Significance of difference has been found between the group of old age men and women on the scale of Social Support towards their degree of life satisfaction.

4. Old age women were found more prone to social support than old age men to maintaining their over all life satisfaction especially in New Delhi.

5. On the basis of past researches and observations the important conclusions are summed up. The studies and its discussions mentioned above seem to be the reasons because of the fact that social support especially from informal social networking from the side of members of home either they live in joint family or nuclear family especially during this period of novel COVID - 19 pandemic are always needed for successful aging. This is only the way by which life satisfaction with positive sense of commitment and work ethics can be maintained without having any feeling of shyness, inferiority and sense of loosing esteem needs, etc. It is often seen that joint family provides social supports to the weak, aged, sick and disabled person. Hence, social security, emotional support, and sympathy become more important for the old age. It is often seen that being the elder member of the joint family the elders of old age members are obeyed, their inner feelings are recognized, and thus their status is not undermined. So, the old age members of the joint family experience less depression, anxiety, stress and harassment in comparison to those old age members who are living in nuclear family set-up. Further empirical and theoretical researches on different aspects relating to aging is needed during the periods of novel COVID - 19 breaks especially in New Delhi - India to understand the behavior of aged. It is because of the fact that they have contributed a lot to the betterment of society in general and their services for the development of nation can not be overlooked.

\section{REFERENCES}

1. George, L. K. (1981). Subjective well-being conceptual and methodological issues in Annual Review of Gerontology and Geriatries, C. Eisclofar (Ed) 2, Spring New York.

2. Hurlock, E. B. (1981). Personality Development. Tata Mc Graw Hill Publishing Co., New Delhi.

3. Palmore, E., \& Kivett, V. (1977). Change in Life Satisfaction: A longitudinal Study of person age 46-70. Journal of Gerontology. 32(3):311-316.

4. Taves, M. J., \& Hansen, G. D. (1962). Seventeen hundred elderly citizens. In Rose, A. M. ed., Aging in Minneapolis Press, Minnesota.

5. Lawton, M. P. (1983). The Philadelphia Geriatric Center morale scale: A revision. Journal of Gerontology. 30(1):85-89.

6. Miller, R. J., \& Misher, E. G. (1964). Social class, mental illness and American Psychology: An exploratory review. In Reizman, F., Cohen, J., \& Pears, A. (Eds.), Mental Health of poor. New York: Free Press.

7. Cobbs, S. (1976). Social support as a moderator of life stress. Psychosomatic Medicine. 38: 300-314.

8. Chadha, N. K., \& Van Willigen, J. (1995). The Life Satisfaction Scale; The development of a measure of successful aging. Indian Journal of Gerontology. 9 93\&4):83-90.

9. Nehra, R., Kulhara, P., \& Verma, S. K. (1998). PGI Social Support Questionnaire. Rupa Psychological Centre, Varanasi, India.

10. Gupta, N. (2011). Insight for Aging: Towards a better and graceful life. PsyInsight, 2(4).

11. Belle, D. (1982). Social network factors associated with perceived quality of life: The San Luis Valley Health and Aging Study. Journal of Aging and Health. 10(3):287-310.

12. Eisenberg, N., \& Lennon, R. (1983). Sex differences in empathy and related capacities. Psychological Bulletin. 94:100-131. 